\title{
Trefoil peptides as proangiogenic factors in vivo and in vitro: implication of cyclooxygenase-2 and EGF receptor signaling
}

\author{
SYLVIE RODRIGUES, ${ }^{1}$ ELISABETH VAN AKEN, ${ }^{*}{ }^{1}$ SASKIA VAN BOCXLAER,* \\ SAMIR ATTOUB, QUANG-DÉ NGUYEN, ERIK BRUYNEEL,* BRUCE R. WESTLEY, ${ }^{\dagger}$ \\ FELICITY E. B. MAY ${ }^{\dagger}$ LARS THIM, ${ }^{\ddagger}$ MARC MAREEL, $*$ CHRISTIAN GESPACH, \\ AND SHAHIN EMAMI ${ }^{2}$ \\ INSERM U482, Signal Transduction and Cellular Functions in Diabetes and Digestive Cancers, \\ Hôpital Saint-Antoine, 75571 Paris Cedex 12, France; *The Laboratory of Experimental Cancerology, \\ Ghent University Hospital, B-9000 Ghent, Belgium; ${ }^{\dagger}$ Department of Pathology, University of \\ Newcastle, Newcastle upon Tyne NE1 4LP, UK; and ${ }^{\ddagger}$ Novo Nordisk, Bagsvaerd, DK-2880, Denmark
}

\begin{abstract}
We previously established that the trefoil peptides (TFFs) pS2, spasmolytic polypeptide, and intestinal trefoil factor are involved in cellular scattering and invasion in kidney and colonic cancer cells. Using the chorioallantoic membrane (CAM) assay and the formation of tube-like structures by human umbilical vein endothelial cells (HUVEC) plated on the Matrigel matrix substratum, we report here that TFFs are proangiogenic factors. Angiogenic activity of TFFs is comparable to that induced by vascular endothelial growth factor, leptin, and transforming growth factor- $\alpha$. Stimulation of angiogenesis by pS2 in the CAM assay is blocked by pharmacological inhibitors of cyclooxygenase COX-2 (NS-398) and epidermal growth factor receptor (EGF-R) tyrosine kinase (ZD1839), but is independent of KDR/Flk-1 and thromboxane A2 receptors. In contrast, the morphogenic switch induced by pS2 in HUVEC cells could be inhibited by the specific KDR heptapeptide antagonist ATWLPPR and by inhibitors of COX-2 and EGF-R signaling. These results implicate TFFs in the formation of new blood vessels during normal and pathophysiological processes linked to wound healing, inflammation, and cancer progression in the digestive mucosa and other human solid tumors associated with aberrant expression of TFFs.Rodrigues, S., Van Aken, E., Van Bocxlaer, S., Attoub, S., Nguyen, Q.-D., Bruyneel, E., Westley, B. R., May, F. E. B., Thim, L., Mareel, M., Gespach, C., Emami, S. Trefoil peptides as proangiogenic factors in vivo and in vitro: implication of cyclooxygenase $\mathbf{- 2}$ and EGF receptor signaling. FASEB J. 17, 7-16 (2003)
\end{abstract}

The hallmark of progression of human colorectal tumors from the early premalignant stages is the acquisition of the invasive phenotype and formation of new blood vessels within the adenomas and adenocarcinomas (1). There is evidence to support a critical role for the inflammatory processes and mucosal ulceration in the emergence of gastrointestinal tumors (2-4). Patients with inflammatory bowel disease have an in- creased risk of developing intestinal neoplasms. Chronic inflammatory disorders, diabetic retinopathy, tissue ischemia, and tumor angiogenesis are characterized by the branching and sprouting of new blood vessels. The development of solid tumors promotes mobilization of the differentiated endothelium of preexisting vascular cells at the vicinity of the neoplastic tissues and the recruitment of bone marrow-derived endothelial progenitors and hematopoietic stem cells (5-7). Angiogenesis also occurs in healthy individuals during wound healing and other physiologic regulations in the female reproductive tract (8). Several clinical and experimental studies indicate that angiogenesis is critical for the growth and persistence of solid tumors and is strongly associated with the metastatic cascade. The coordinated control of tumor cell invasion, survival, and angiogenesis allows tumor cells to invade distant organs during the complex processes of the metastatic cascade. A tumor mass that is smaller than $0.4 \mathrm{~mm}$ in diameter can receive oxygen and nutriments by simple diffusion. However, without surrounding blood vessels, primary colonic tumors $3 \mathrm{~mm}^{3}$ in size are not able to survive (9). Induction of the angiogenic switch is the consequence of local hypoxia and absolute requirements of growing primary tumors on oxygen, nutriments, and survival factors (9-11). The formation of new vascular structures during cancer progression is primarily mediated by the proliferation, migration, and morphogenesis of endothelial cells induced by proangiogenic and chemotactic factors stimulating the migratory phenotype through direct and indirect mechanisms involving paracrine and autocrine regulatory loops. Thus, numerous angiogenic factors are produced locally by cancer cells, endothelial cells, and stromal and blood cells. Positive and negative

\footnotetext{
${ }^{1}$ These authors contributed equally to this work.

${ }^{2}$ Correspondence: INSERM Unit U482, Hôpital Saint-Antoine, 75571 Paris Cedex 12, France. E-mail: emami@ st-antoine.inserm.fr
} 
regulators of angiogenesis are stored in the ECM as active or inactive forms, at the multiple interfaces between tumor cells and the other cell types within the tumor stroma. Tumor angiogenesis and vascular remodeling during chronic inflammation are controlled by numerous angiogenic activators and mitogens such as vascular endothelial growth factors (VEGFs), fibroblast growth factors, cyclooxygenase COX-2, transforming growth factor- $\beta$ (TGF- $\beta$ ), and agonists of the epidermal growth factor receptors (EGF-R) such as TGF- $\alpha$ $(10-15)$. Accordingly, we recently demonstrated that the neoplastic progression of human colorectal tumors is associated with early and sustained increase in VEGF transcripts and expression of members of the VEGF family (VEGF-B, VEGF-C) and their tyrosine kinase receptors FLT-1, KDR, and FLT-4 (1).

Trefoil peptides (TFFs) are overexpressed during peptic ulceration, in inflammatory bowel diseases (Crohn disease, colitis), and during the early stages of human colon cancer progression $(16,17)$. The trefoil peptide family, comprising pS2, spasmolytic polypeptide (SP) and intestinal trefoil factor (ITF), plays a key role in wound healing and mucosal repair in the digestive tract, tumor cell scattering, migration, survival, and invasiveness (16-23). Overexpression of TFFs and pS2 was originally observed in several solid human tumors including breast, pancreas, prostate, and stomach $(16,24-28)$, suggesting local autoregulation of transforming functions by trefoil peptides (17). Expression of the breast cancer-associated pS2 peptide is closely associated with premalignant stages in human gastric mucosa (24) and with neuroendocrine differentiation of prostate cancers via an estrogen-independent pathway $(25,27)$. In agreement, pS2 was negative in patients with benign prostate hyperplasia whereas $92 \%$ of patients at risk with prostate cancer are positive for pS2 expression (28). Recent studies designated the possible contribution of the EGF-R mitogen-activated protein kinase cascade in trefoil peptide-mediated signaling, leading to decreased cell-cell and cell-substratum adhesion (23) or transcriptional inter-regulations $(29,30)$. We recently demonstrated that external addition of TFFs or constitutive overexpression of pS2 promotes cellular scattering and invasion in kidney and colonic epithelial cells through cyclooxygenase- and thromboxane A2 receptor (TXA2-R) -dependent mechanisms $(17,19)$. These two cellular activities implicated in tumor cell invasion and metastasis are required for endothelial cell migration, proliferation, and formation of new microvasculature during establishment of the angiogenic cascade in solid tumors. Therefore, we reasoned that TFFs might also exert angiogenic functions in normal physiological processes during embryonic development and formation of vascular-like structures by endothelial cells in vivo and in vitro.

In this study, we set out to compare the angiogenic potential of trefoil peptides and well-recognized proangiogenic factors, including the secreted form of VEGF165 , TGF- $\alpha$, and leptin $(13,31)$. We first examined the angiogenic activity of the trefoil factors $\mathrm{pS} 2, \mathrm{SP}$, and
ITF on the chick chorioallantoic membrane (CAM) assay. The possible implication of COX-2 and the EGF-R was examined, with special reference to the EGF-R tyrosine kinase inhibitor ZD1839 (Iressa), an anilinoquinazoline derivative that blocks transforming functions controlled by the EGF-R agonists TGF- $\alpha$, amphiregulin, and EGF in kidney and colonic cancer cells $(32,33)$. Second, we investigated the capacity of TFFs to induce the formation of capillary-like structures by primary human umbilical vein endothelial cells (HUVEC) in culture (34). Using these experimental approaches, we now provide evidence that TFFs are functioning as angiogenic factors in vivo and in vitro.

\section{MATERIALS AND METHODS}

\section{Cell culture}

Primary cultures of HUVEC were obtained from CloneticsBioWhittaker (Emerainville, France) and maintained at $37^{\circ} \mathrm{C}$ using the EBM-2 bullet kit from BioWhittaker supplemented with $2 \%$ fetal calf serum, endothelial cell growth supplement (containing VEGF, human FGF-B, IGF-1, and human EGF), $50 \mu \mathrm{g} / \mathrm{mL}$ heparin, $100 \mathrm{IU} / \mathrm{mL}$ penicillin, $100 \mu \mathrm{g} / \mathrm{mL}$ streptomycin, $2.5 \mu \mathrm{g} / \mathrm{mL}$ amphotericin $\mathrm{B}$, and supplements hydrocortisone, ascorbic acid, gentamicin, and insulin (BioWhittaker). Cells used in the experiments were between passages 5 and 15.

\section{Chick CAM assay}

The CAM angiogenesis assay was performed as described by Maragoudakis et al. (35), with some modifications (36). Fertilized chicken eggs (Nauwelaerts, Oostakker, Belgium) were incubated for 3 days at $37^{\circ} \mathrm{C}$ with $70 \%$ humidity. On day 3 , albumen was removed to detach the developing CAM from the shell. On day 4, a small window was opened on the eggshell (exposing the CAM) and covered with cellophane tape. The eggs were returned to the incubator until day 9, when the test compounds diluted at the indicated concentrations in control vehicle buffer $(250 \mu \mathrm{L}$ were placed on sterile plastic disks (11 mm diameter), which were allowed to dry under sterile conditions. A solution of cortisone acetate (100 $\mu \mathrm{g}$ /disk; Sigma; Saint-Quentin Fallavier, France) was incorporated in all disks. On each CAM, the disk containing control vehicle was placed $1 \mathrm{~cm}$ away from the disk containing the test compound. The windows were covered and eggs were incubated until day 11, when angiogenesis was assessed. The eggs were flooded with $10 \%$ buffered formalin, the plastic disks were removed, and the eggs were kept at room temperature for at least $2 \mathrm{~h}$. A large area around the disks was cut off and placed on a glass slide, and the vascular density index was measured by the method of Harris-Hooker et al. (37). A grid containing three concentric circles of 6,8 , and $10 \mathrm{~mm}$ diameter was positioned on the CAM surface. Each experimental determination involved counting of angiogenic vessels on five to eight separate eggs. All vessels intersecting the circles were counted. Most stimulation and inhibition experiments were repeated one to four times together with buffer vehicle controls. The angiogenic response in a given CAM assay was analyzed using the box plot representation (38) in which each box bounds the first and third quartiles (referred to as the interquartile range) encompassing $50 \%$ of the data and includes the median, upper, and lower hinges, as indicated by horizontal lines within the box. Dispersion of the 
data above and below this range is marked by vertical bars that extend to the most extreme values, including the adjacent values inside the upper and lower fences, and by individual outliers beyond this range (filled circles). The box plot illustrates unusual distributions, sample size in each group, and the confidence interval about the median. The significance of the differences between experimental values was assessed by the Mann Whitney-U test and $P$ values $<0.05$ were considered to be statistically significant.

\section{In vitro capillary formation of HUVEC cells plated on Matrigel}

Assessment of in vitro capillary formation used growth factorreduced Matrigel (Becton Dickinson, Le Pont de Claix, France). Matrigel is a squamous cell carcinoma basement membrane matrix composed primarily of collagen IV, laminin, entactin, and heparan sulfate proteoglycans. The Matrigel matrix was thawed, gently mixed to homogeneity using cooled pipettes, and diluted $\mathrm{v} / \mathrm{v}$ with the EBM-2 culture medium (BioWhittaker France). Matrigel supplemented or not with angiogenic peptides and other effectors was used to coat the wells of 96-well plates. After solidification of the Matrigel suspension (50 $\mu$ Lwell) for $1 \mathrm{~h}$ at $37^{\circ} \mathrm{C}, \sim 35,000$ HUVECs were plated to each well and incubated for 4 and $8 \mathrm{~h}$ at $37^{\circ} \mathrm{C}$ in $0.2 \mathrm{~mL}$ of EBM-2 medium containing $2 \% \mathrm{FCS}$, heparin, hydrocortisone, ascorbic acid, and gentamicin without endothelial cell growth supplement. Then cells were photographed using a Nikon inverted phase contrast photomicroscope (Nikon, Eclipse TE300, Micromécanique, Evry, France) coupled with video image analysis (Micromécanique). The tubular network growth area was compared in control and effector-treated Matrigel matrix. Tube formation was quantified by counting the number of tube-like structures formed in each microwell.

\section{Peptides and Chemicals}

Human SP and ITF were produced in yeast and purified as described $(39,40)$; the recombinant $\operatorname{Ser}_{58}$ analog of human pS2 produced in Escherichia coli was purified by affinity and ion exchange chromatography, followed by gel filtration (41). VEGF-165 and leptin were from R\&D System Europe Ltd.(Oxon, UK). The EGF-R agonist TGF- $\alpha$ was from Sigma. The selective COX-2 inhibitor NS-398 and the JAK-2 tyrosine kinase inhibitor AG490 were from Calbiochem (Meudon, France). The EGF-R tyrosine kinase inhibitor ZD1839 (Iressa), also designated ZD in the present study, was from AstraZeneca (Macclesfield, UK). In tyrosine kinase assays, the inhibitory potency of ZD1839 on the EGF-RTK occurs at $\mathrm{IC}_{50}$ concentrations ranging from 23 to $80 \mathrm{nM}$ (42). Inhibition of the KDR and c-erbB-2 tyrosine kinases occurs, but at doses 100 -fold higher than EGF-RTK inhibition. No other activity has been demonstrated against a wide range of other kinases. The prostaglandin H2/TXA2-R antagonist SQ29,548 (designated as SQ295 in the present study) was from Cayman Chemicals (Ann Arbor MI, USA). The KDR antagonist ATWLPPR (43), designated A7 in the present study, was from Neosystem (Strasbourg, France).

\section{RESULTS}

\section{Induction of angiogenesis in vivo by trefoil peptides in the CAM assay}

We performed initial experiments to test the ability of recombinant trefoil peptides (TFFs) to function as proangiogenic factors in vivo. We used the CAM assay involving the coordination and integration of multicellular responses during development of the chick embryo.

As shown in Fig. 1, pS2, SP, and ITF promoted a remarkable stimulation of new vessel formation that was comparable to that induced by the proangiogenic factor VEGF-165. Angiogenic activity of the trefoil peptides was dose dependent for both pS2 and ITF (Fig. 2), with a threshold stimulation observed at the dose of $1.75 \mathrm{ng} \mathrm{pS2/disk}(P<0.01)$ and $16.7 \mathrm{ng} \mathrm{ITF/}$ disk $(P<0.01)$ compared with the control DMEM medium.

The possible contribution of VEGF receptors to angiogenesis promoted by external addition of the trefoil factor pS2 was investigated in the CAM assay. We tested blocking activity of the ATWLPPR heptapeptide (A7), which was recently shown to abolish VEGFinduced angiogenesis in vivo, through direct binding to KDR and competition against the functional interactions between VEGF and KDR (43). Indeed, VEGF is thought to induce angiogenesis by engaging VEGF receptors 2 (VEGF-R2), also known as KDR and Flk-1. As shown in Fig. 3, the blocking peptide was inefficient

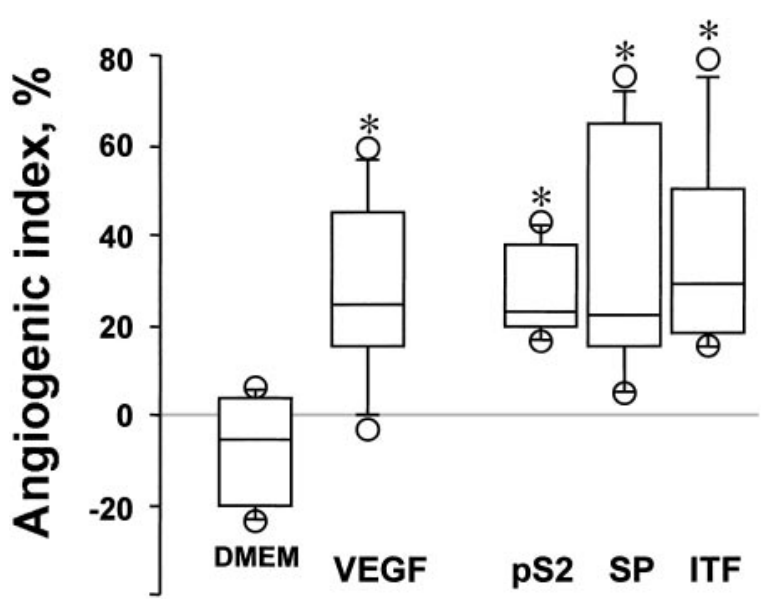

Figure 1. Chorioallantoic membrane angiogenesis induced by trefoil peptides and VEGF. On day 9, each CAM was exposed to either $55 \mathrm{nM}$ VEGF-165 (250 ng/disk) or the trefoil peptides $\mathrm{pS} 2$, SP, and ITF $(100 \mathrm{nM})$ as a solution corresponding to $175 \mathrm{ng} \mathrm{pS} 2,300 \mathrm{ng} \mathrm{SP}$, and $167 \mathrm{ng}$ ITF/disk. DMEM refers to the buffer control used as vehicle. After $48 \mathrm{~h}$ of incubation, CAMs were examined with a macroscope to count the angiogenic vessels. Each substance was analyzed with 8 embryos in parallel as described in Materials and Methods. Angiogenesis was scored in a double-blind procedure for each embryo by estimating the number and extent of vessel branch points in the area of the disk. The angiogenic activity in the CAM assay is calculated from the formula: angiogenic index $=(\mathrm{t}-\mathrm{c}) / \mathrm{c} \times 100$, where $\mathrm{t}$ equals the number of intersections in the area covered by the test disk and $\mathrm{c}$ the number of intersections of any vessel in the area covered by the control disk in the same egg. The significance of the differences between the control angiogenic index (DMEM) and the other experimental values was assessed by the Mann Whitney test. $P$ values $<0.05$ were considered to be statistically significant. All growth factors considered induced significant stimulation of angiogenesis $(* P<0.01)$. 


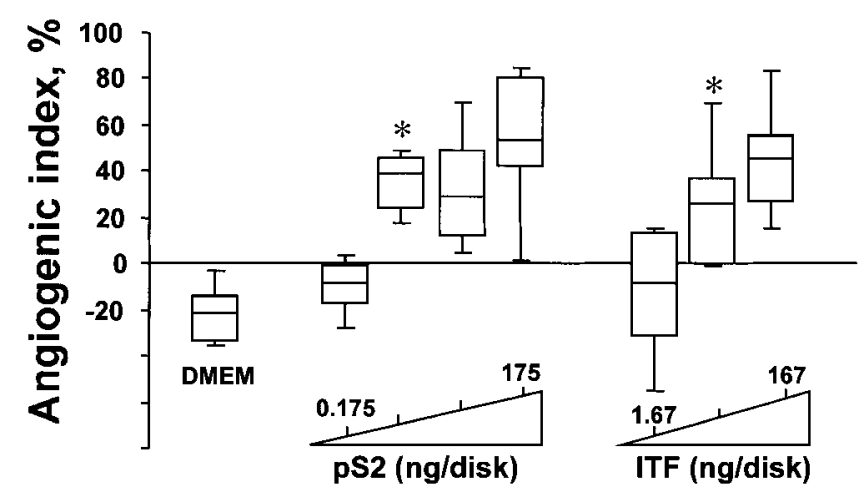

Figure 2. Dose-dependent stimulation of chorioallantoic membrane angiogenesis by the trefoil peptides pS2 and ITF. Chorioallantoic membranes were treated with various concentrations of pS2 (0.1-100 nM) as a solution containing different amounts of trefoil peptides (0.175-175 ng pS2/disk) and ITF (1-100 nM, 1.67 to $167 \mathrm{ng} /$ disk). After $48 \mathrm{~h}$ of incubation, CAMs were examined with a macroscope to count the angiogenic vessels. Significance of the differences between the control angiogenic index (DMEM) and other experimental values was assessed by the Mann Whitney test. Threshold stimulations compared with the control DMEM, $* P<0.01$.

against the angiogenic response induced by pS2 in the CAM assay, but abolished the formation of new blood vessels induced by VEGF-165. The KDR antagonist A7 alone was ineffective on control angiogenic activity. Thus, A7 selectively prevented angiogenesis promoted by VEGF in our CAM assay.

We next investigated the potential role of the EGF-R signaling pathway in angiogenesis evoked by VEGF, leptin, and pS2. The EGF-R is activated by a family of regulatory growth factors including EGF, TGF- $\alpha$, and amphiregulin. EGF and TGF- $\alpha$ are overexpressed in gastrointestinal cancer cells and act as paracrine and autocrine mitogenic and angiogenic agents in human digestive cancer and other solid tumors of breast, prostate, and pancreas (13, 44-46). As shown in Fig. 4, addition of the EGF-R agonist TGF- $\alpha$ in the CAM assay dose-dependently increased angiogenesis; this was abolished by simultaneous addition of the EGF-R tyrosine kinase inhibitor ZD1839 (ZD). The antitumor effect of ZD1839 was accompanied by inhibition of microvessel counts in human colonic xenografts and depletion of proangiogenic growth factors such as VEGF, TGF- $\alpha$, and fibroblast growth factor (47). Similarly, ZD1839 reversed by $70 \%$ the VEGF angiogenic activity in our studies, whereas the formation of new blood vessels induced by pS2 was completely suppressed by this tyrosine kinase inhibitor. Our findings imply that the proangiogenic effect of $\mathrm{pS} 2$ is highly dependent on the functional activity of the EGF-R. Consistent with our data, recent studies indicate that ITF signaling is linked to transactivation of the EGF-R tyrosine kinase during establishment of the migratory phenotype in human colonic cancer cells HT29 (23, 30). In contrast, leptininduced angiogenesis was not inhibited by ZD1839 but was completely inhibited by the Janus kinase JAK-2 tyrosine kinase inhibitor AG490 (Fig. 4). Indeed, leptin receptors $\mathrm{Ob}-\mathrm{Rb}$ were shown to oligomerize and, upon leptin interaction, activate JAK-2 via transphosphorylation (48). Conversely, AG490 did not inhibit pS2induced angiogenesis. We found that ZD1839 specifically inhibited proangiogenic signals induced by TGF- $\alpha$, VEGF, and pS2 and did not affect angiogenesis linked to the activation of the Ob-Rb by leptin. Thus, our data reveal that the EGF-R is implicated in the proangiogenic activity of VEGF and pS2 using the CAM assay.

We have reported that trefoil peptides exert scattering and proinvasive activities in kidney and colonic cancer cells through cyclooxygenase- and TXA2-R-dependent signaling pathways $(17,19)$. Elevated levels of cyclooxygenase COX-2 are detected at an early stage in colorectal neoplasia during adenoma formation and in adenocarcinomas (49-51). COX-2 is frequently undetectable in normal tissues but is induced in gastrointestinal epithelial cells and endothelial cells in response to hypoxia, inflammatory cytokines, oxygen radicals, and cellular transformation by the SRC oncogene $(19,52)$. In solid tumors, COX-2 is localized in neoplastic cells, microvascular endothelial cells, interstitial macrophages, and stromal fibroblasts. The contribution of COX-2 in tumor angiogenesis (53) is associated with increased expression of VEGF (54), production of the eicosanoids TXA2, PGE2, and prostacyclins that are directly involved in the migratory and invasive phenotypes of endothelial and tumor cells $(19,55-57)$. Prostaglandins E2 in turn were recently shown to transactivate the EGF-R, a signaling response directly connected with the growth of colon cancer (58). Therefore, COX-2 signaling through its eicosanoid products plays a key role in inflammation, carcinogenesis, tumor invasion, and angiogenesis in several solid tumors of the gastrointestinal tract, breast, and prostate. Several experimental and clinical studies have demonstrated

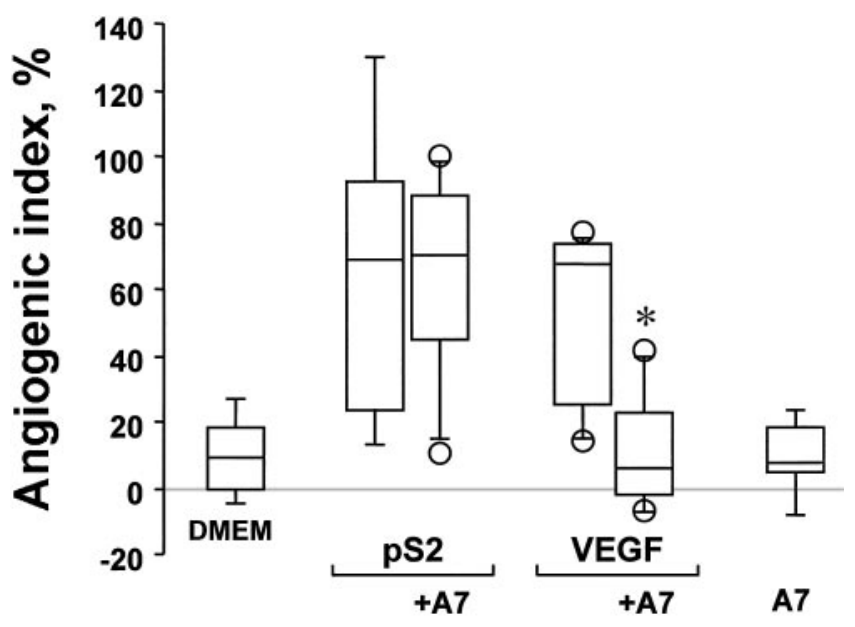

Figure 3. Effect of the KDR antagonist A7 on chorioallantoic membrane angiogenesis induced by $\mathrm{pS} 2$ and VEGF. The ATWLPPR heptapeptide A7 (200 $\mu \mathrm{M}, 42 \mu \mathrm{g} /$ disk) efficiently and specifically inhibited the angiogenic response produced by VEGF-165 $(250 \mathrm{ng} /$ disk $)$ in the CAM assay $(* P<0.01)$ but was ineffective on the proangiogenic activity of pS2 (100 nM, $175 \mathrm{ng} \mathrm{pS2/disk).}$ 


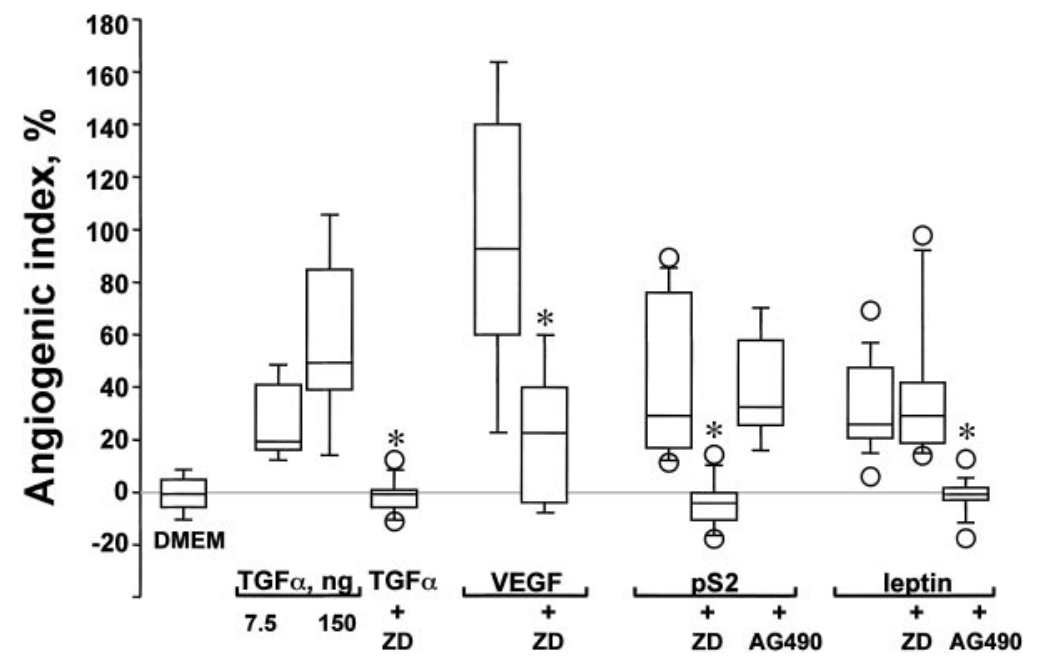

Figure 4. Effect of the tyrosine kinase inhibitors ZD1839 and AG490 on chorioallantoic membrane angiogenesis induced by TGF- $\alpha$, VEGF, pS2, and leptin. Angiogenesis was strongly induced by increasing concentrations of the EGF-R agonist TGF- $\alpha$ ( 5 and $100 \mathrm{nM}$, corresponding to 7.5 and $150 \mathrm{ng}$ TGF- $\alpha /$ disk, respectively) or single addition of VEGF (250 ng/disk), pS2 (175 ng/disk), and $6.25 \mathrm{nM}$ leptin $(100 \mathrm{ng} / \mathrm{mL}, 25 \mathrm{ng} /$ disk $)$. The EGF-R tyrosine kinase inhibitor ZD1839 (1 $\mu \mathrm{M}$, $112 \mathrm{ng} /$ disk) abrogated the angiogenic response promoted by TGF- $\alpha$ (100 nM, $150 \mathrm{ng} /$ disk) or $\mathrm{pS} 2$ $(* P<0.01)$, reduced by $75 \%$ the stimulatory effect of VEGF $(P<0.04)$, but was ineffective on the proangiogenic activity of leptin. In contrast, JAK-2 tyrosine kinase inhibitor AG490 $(50 \mu \mathrm{M}, 3.65$ $\mu \mathrm{g} /$ disk) selectively blocked leptin-induced angiogenesis. that nonsteroidal anti-inflammatory drugs such as sulindac, piroxicam, and NS-398 inhibit angiogenesis through direct effects on endothelial cells. These COX-2 inhibitors reduce the number and size of intestinal polyps in patients with familial adenomatous polyposis and abolish tumor cell invasion induced by trefoil peptides and the SRC oncogene (19, 59-61). Because COX-2 has been implicated in endothelial cell motility and formation of capillary-like structures through a TXA2-R dependent mechanism $(55,62)$, we next examined the possible contribution of COX-2 and the TXA2-R in the determination of proangiogenic activity of $\mathrm{pS} 2$ in the CAM assay.

We tested the effect of the COX-2 inhibitor NS-398 at a starting concentration of $100 \mathrm{nM} \mathrm{(7.8} \mathrm{ng/disk)}$ corresponding to total inhibition of cellular invasion and TXA2 production induced by $\mathrm{pS} 2$ and src in HCT8/S11 human colonic cancer cells (19). Under these conditions, NS-398 abrogated angiogenesis induced by VEGF and pS2 (Fig. 5). In contrast, the TXA2-R antagonist SQ295 was ineffective against the angiogenic response evoked by pS2. In agreement, CAM angiogenesis was not affected by the TXA2-R agonist U466 (not shown), suggesting that the proangiogenic effect of pS2 is independent of TXA2 and its receptors. Of several positive angiogenic factors produced by cyclooxygenases, PGE2 was recently demonstrated to induce VEGF expression in rat gastric microvascular endothelial cells, suggesting that autocrine VEGF regulation of endothelial cell proliferation, migration, and morphogenesis can take place in tumor angiogenesis (57). There is solid evidence that hypoxia signals and disruption of intercellular junctions between endothelial cells involving the VE-cadherin system up-regulate VEGF generation by endothelial cells $(8-11,63-65)$. Consistent with these findings, the existence of an autocrine loop for induction of the VEGF gene and accumulation of VEGF through activation of the VEGF receptor $\mathrm{KDR}$ has been reported in human dermal microvascular endothelial cells (66). These observations suggest that angiogenesis involves a self-amplification mechanism that is primed by VEGF produced by tumor cells in a first step, then by autoin- duction of VEGF expression in endothelial cells. Accordingly, Fig. 5 shows that simultaneous addition of VEGF and pS2 did not produce additive responses. Thus, single addition of each proangiogenic peptide induced maximal stimulation and saturation of the angiogenic capacity in the CAM assay.

\section{Induction of capillary-like structures in HUVEC by trefoil peptides in vitro}

To assess whether the proangiogenic effect of TFFs involves a direct interaction of the peptides with endothelial cells, we conducted comparative studies on the formation of capillary-like structures in vitro, using HUVEC plated on Matrigel-coated plates. As shown in Fig. 6A, normal and transformed human endothelial cells have the ability to form capillary structures when seeded and cultured for $8 \mathrm{~h}$ on top of Matrigel substratum $(34,66,67)$. Control cells move from their initial

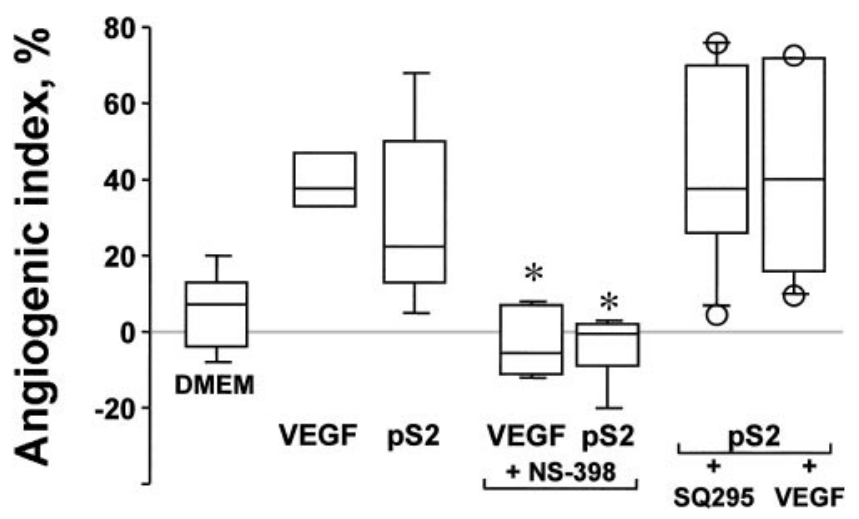

Figure 5. Effect of the cyclooxygenase COX-2 inhibitor NS398 and the TXA2-R antagonist SQ295 on chorioallantoic membrane angiogenesis induced by VEGF and pS2. The COX-2 inhibitor NS-398 (100 nM, $7.8 \mathrm{ng} /$ disk) inhibits VEGF- and pS2-induced angiogenesis in the chicken CAM $(P<0.01$ and $P<0.005$, respectively; $* P<0.01)$, whereas the TXA2-R antagonist SQ295 (30 $\mu \mathrm{M}, 2.9 \mu \mathrm{g} /$ disk) was ineffective. Nevertheless, combined addition of VEGF and pS2 showed no additional response compared with the angiogenic index measured in the presence of each effector alone. 
uniform pattern of dispersed cell layers and associate to form a network of cell clusters connected by long, multicellular processes leading to the formation of tube-like structures. This spontaneous angiogenic phenotype is enhanced by addition of the growth factors VEGF, pS2, and leptin in the Matrigel matrix (Fig. $6 \mathrm{~A}$ and Fig. 7) and involves endothelial cell migration and capillary tube formation. Simultaneous addition of the KDR inhibitor A7 resulted in a strong inhibition of the angiogenic responses to VEGF and pS2 (Fig. 6A and Fig. 7). Similarly, up to $60-70 \%$ inhibition of tube-like structures induced by VEGF and pS2 was observed in HUVEC cell cultures treated by EGF-R and COX-2 inhibitors (Fig. $6 B$ and Fig. 7). However, the KDR antagonist A7 and the COX-2 inhibitor NS-398 were ineffective against the migratory phenotype induced by leptin in HUVEC grown on Matrigel (Figs. 6 and 7). The crucial role of the EGF-R in angiogenesis is further supported by the observation that the capillary-like structures in HUVEC cells were interrupted by the tyrosine kinase inhibitor ZD1839.

\section{DISCUSSION}

We show in this study that trefoil peptides are proangiogenic regulators in vivo and in vitro, suggesting direct interactions between these gastrointestinal peptides and endothelial cells. The VEGF receptor KDR seems to mediate almost all the observed angiogenic responses to VEGF-165 in the CAM assay and the formation of tube-like structures induced by VEGF and pS2 in HUVEC, using growth factor-reduced conditions in the culture medium and Matrigel matrix substratum.

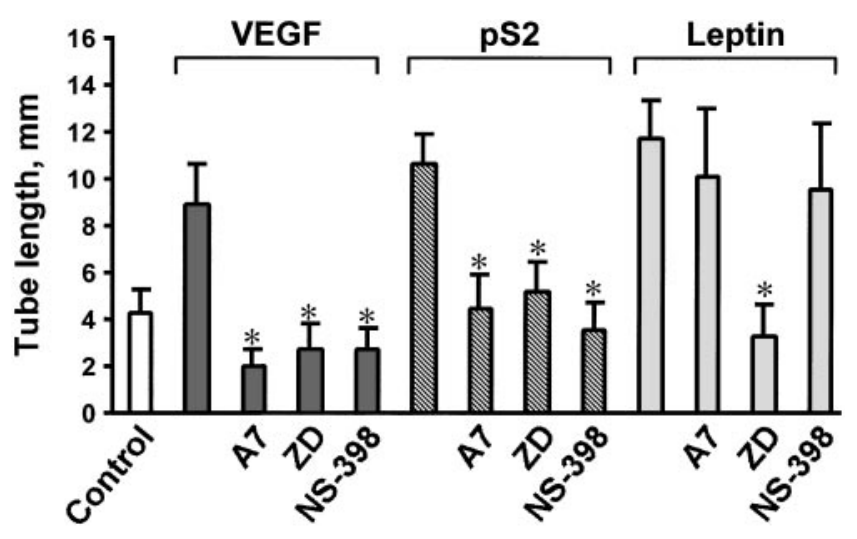

Figure 7. Quantification of tubular morphogenesis induced by VEGF, pS2, and leptin in HUVEC cells cultured in the presence or absence of the KDR antagonist A7 and pharmacological inhibitors of the EGF-R tyrosine kinase (ZD1839) and COX-2 (NS-398). HUVEC cells were cultured under the experimental conditions described in legend to Fig. 6. Tube formation was determined by the length of tube-like structures containing connected cells. Data are means \pm SE from 4 separate experiments. Asterisks indicate that significantly different values were obtained in the presence of the indicated inhibitors vs. the corresponding control stimulation $(P<0.001-0.024$, unpaired Student's $t$ test $)$.

In contrast, angiogenesis promoted by $\mathrm{pS} 2$ in the CAM assay was not abolished by the KDR antagonist A7, suggesting functional redundancies in vivo and a permissive action of KDR signaling on the proangiogenic activity of pS2 on endothelial cells in vitro (Fig. 8). Accordingly, the spontaneous angiogenic phenotype was blocked effectively in control HUVEC incubated for 8 and $16 \mathrm{~h}$ in the presence of the KDR antagonist $\mathrm{A} 7$
A
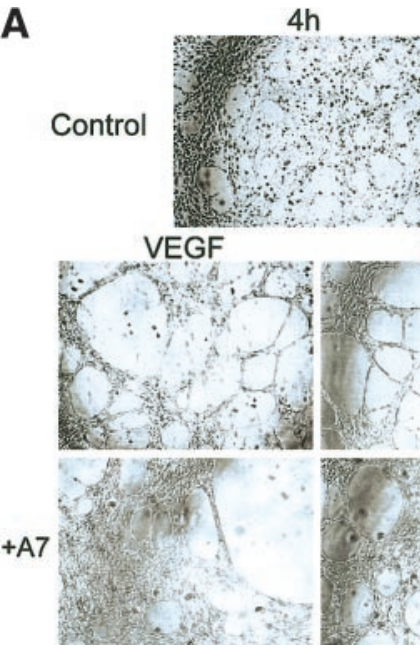

$8 \mathrm{~h}$

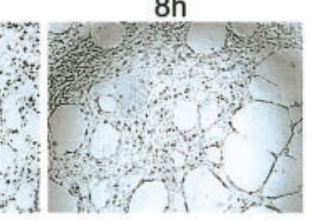
pS2

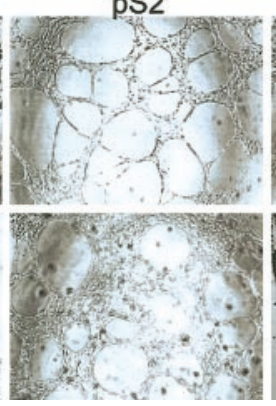

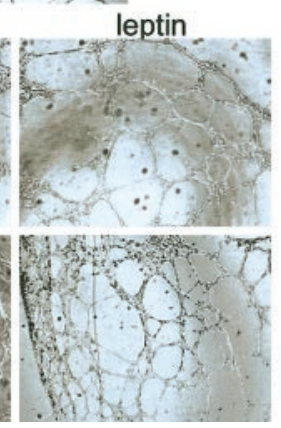

B
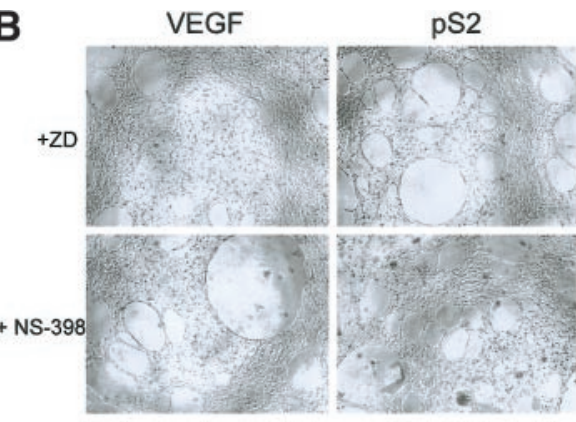

leptin

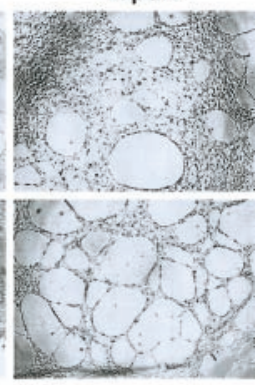

Figure 6. Patterns of angiogenesis induced by human umbilical vein endothelial cells (HUVEC) cultured on Matrigel matrix in the presence or absence of the proangiogenic factors VEGF-165, pS2, and leptin: selective inhibition by the KDR antagonist A7 and inhibitors of the EGF-R tyrosine kinase (ZD1839) and cyclooxygenase COX-2 (NS-398). Cultured HUVEC cells were plated onto layers of growth factor reduced basement membrane Matrigel matrix containing the following proangiogenic factors: VEGF $(2.2 \mathrm{nM})$, pS2 $(100 \mathrm{nM})$, leptin $(6.25 \mathrm{nM})$, or control buffer containing $2 \%$ FCS, as vehicle (control). A) Effects of the KDR antagonist A7 $(50 \mu \mathrm{M})$ and $B$ ) inhibitors of the EGF-R tyrosine kinase (ZD1839, $1 \mu \mathrm{M})$ and COX-2 (NS-398, $100 \mathrm{nM})$. Cells were photographed 4 and $8 \mathrm{~h}$ after plating 35,000 HUVEC in 96-well plates. Photographs (magnification: 40×) are representative of 3 other experiments using two separate microwells, illustrating the whole surface of each well. For quantification, see Fig. 7. 


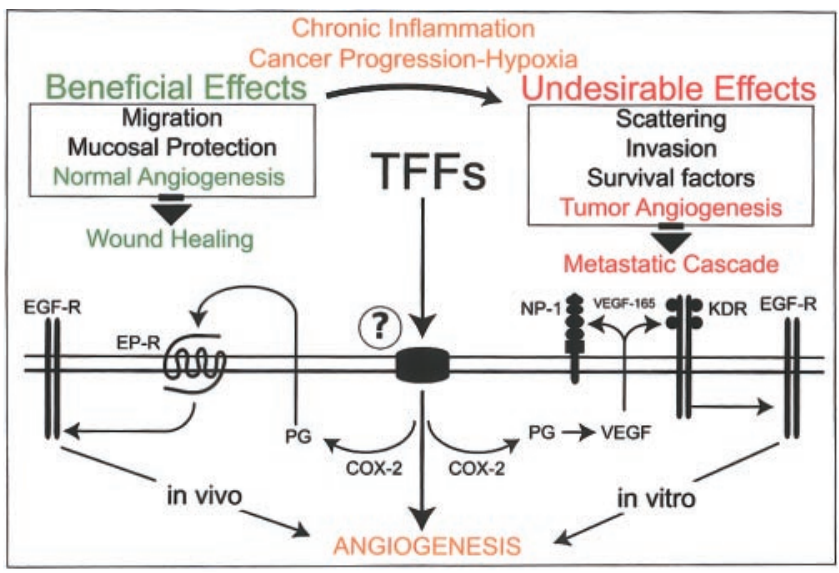

Figure 8. Proposed model of the proangiogenic activity of TFFs in vivo and in vitro. Cyclooxygenase COX-2 and the EGF-R exert critical roles in the proangiogenic functions controlled by TFFs through KDR-dependent and -independent signaling pathways, according the cellular context in vivo and in vitro. The COX-2 product PGE2 (PG) has been reported to trans-activate the EGF-R and to up-regulate the expression and release of VEGF from endothelial cells through the prostaglandin EP receptor (EP-R). Similarly, VEGF-driven angiogenic responses are mediated by KDR and require the concerted activity of $\mathrm{COX}-2$ and the EGF-R tyrosine kinase in vivo and in vitro. A possible contribution of the membrane receptors neuropilins (NP-1 and NP-2) in the proangiogenic activity of trefoil peptides in vitro should be considered, in view of their ability to interact with VEGF $_{165}$. For example, NP-1 was shown to enhance the binding of $\mathrm{VEGF}_{165}$ to KDR and potentiate $\mathrm{VEGF}_{165}$-dependent migration of endothelial cells through the formation of a heterotrimeric complex. Together, our data suggest that trefoil peptides are acting as beneficial proangiogenic factors during normal vascularization, wound healing, and mucosal protection. Conversely, our data also support that TFFs can mediate adverse effects on tumor angiogenesis, invasion, and resistance to apoptosis during neoplastic progression.

(not shown), suggesting self-activation of the VEGF-R KDR/Flk-1 through autocrine loops. A similar situation was observed for the proangiogenic activity of leptin, acting via EGF-R independent pathways in the CAM assay, whereas the EGF-R tyrosine kinase inhibitor ZD1839 abrogated leptin-induced tube-like formation in HUVEC. Thus, the EGF-R is required for the proangiogenic action of leptin in vitro, suggesting the interesting hypothesis that the morphogenic effect of leptin is dependent on the functional activity of the EGF-R tyrosine kinase. For elucidation of the underlying mechanism of $\mathrm{VEGF}_{165^{-}}$and $\mathrm{pS} 2$-induced angiogenesis in HUVEC cells, recent studies have demonstrated that $\mathrm{VEGF}_{165}$ bind with high affinity to the neuropilin receptors NP1 and NP2 (68). NP1 is a multifunctional $130 \mathrm{kDa}$ transmembrane receptor binding placenta growth factor-2, heparin, and semaphorin 3A, a completely unrelated protein family implicated in axon guidance and cell migration $(69,70)$. In contrast, NP2 binds to semaphorin $3 \mathrm{C}$ and $3 \mathrm{~F}$ with high affinity and mediates repulsion of sympathetic neurons (70). Expression of NP1 in endothelial cells enhances affinity labeling of $\mathrm{VEGF}_{165}$ to the VEGFR-2 KDR/Flk-1 recep- tor and $\mathrm{VEGF}_{165}$-induced endothelial chemotaxis (71). Since NP1 forms a coreceptor complex with KDR/Flk-1 in the presence of the $\mathrm{VEGF}_{165}$ ligand (73), it is tempting to consider that NP1 govern, at least in part, the substantial proangiogenic activity of $\mathrm{pS} 2$ and VEGF $_{165}$ at the NP1 and/or NP1-KDR receptor complex in HUVEC. Thus, neutralization of VEGFR-2 by the A7 blocking peptide in the present study might affect the angiogenic responses mediated through the KDR-NP1 complex. Because the HUVEC are reported to contain functional NP1 $(71,72)$, our data leave open the interesting question of whether neuropilins and their ligands, including the potent angiogenic factor

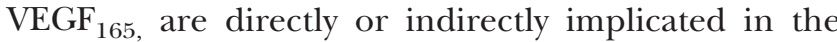
proangiogenic functions of trefoil peptides (Fig. 8). Further studies are required, using neutralizing antibodies directed against NP1 or NP2 or an antagonist peptide that competes for VEGF-165 binding at the KDR/NP1 complex (72).

We have demonstrated that angiogenesis promoted by VEGF and pS2 in vivo and in vitro was prevented by inhibitors of the EGF-R tyrosine kinase (ZD1839) and COX-2 (NS-398). Our data further implicate cyclooxygenases and EGF-R signaling pathways in the determination of the angiogenic phenotype in normal and pathological processes. In contrast, leptin was found to promote formation of tube-like structures in HUVEC in a COX-2 and KDR -independent manner. As expected, the proangiogenic activity of leptin was prevented by the JAK-2 tyrosine kinase inhibitor AG490 in the CAM assay. The signaling capacity of activated $\mathrm{Ob}-\mathrm{Rb}$ include JAK-2 activation, direct recruitment of STAT3 and the tyrosine phosphatase SHP-2, and a number of downstream signals linked to immediate and delayed cellular responses regulating cell proliferation, invasion, and transcriptional regulations $(48,73)$. VEGF-driven angiogenic responses are mediated by $\mathrm{KDR}$ and require the concerted activity of COX-2 and the EGF-R tyrosine kinase in vivo and in vitro. Most interestingly, when the CAM was exposed to the conditioned media (CM-pS2) prepared from pS2-transformed HCT8/S11-pS2 human colonic cancer cells (19), a strong angiogenic response was observed, using an A7- and KDR-dependent pathway (not shown). Control CM prepared from parental HCT8/S11 cells was inactive. Our data support the existence of a proangiogenic factor secreted by pS2-transformed cancer cells and during inflammatory responses associated with pS2 overexpression.

Trefoil peptides have been shown to mediate physiologic functions in the normal digestive tract linked to maintenance of the integrity of the gastrointestinal mucosa. These beneficial functions controlled by TFFs include wound repair and mucosal protection against local injury induced by ulceration and inflammatory and apoptotic signals (16). We have added important information that the beneficial effects of TFFs result from their ability to act as proangiogenic factors in normal endothelial cells. Thus, we have determined that TFFs can contribute to physiological processes in which neovascularization plays an important role dur- 
ing normal development. Conversely, we have previously shown that TFFs can exert undesirable effects in the context of neoplasia by acting as scatter factors and proinvasive agents on cancer cells $(17,19,20)$. This latter prediction is well sustained by the interdependence of TFFs and several signaling pathways playing a key role in the cancerous progression of the human digestive mucosa. These oncogenic pathways include src, the Rho-like small GTPases, PI3'-kinases (17, 19, 20), and signaling through COX-2 and the EGF-R tyrosine kinase in the present study. These signaling pathways play a critical role in endothelial cell proliferation, migration, morphogenesis, and survival. Thus, we hypothesize that TFFs may contribute to tumor angiogenesis and metastasis through the induction of an invasive and angiogenic tumor phenotype. The ITF mRNA and protein are both induced by hypoxia in confluent human colonic epithelial cells Caco-2, in agreement with the presence of the HIF- $1 \alpha$ binding sequence 5'-TACGTGGG-3' identified at positions -129 to -122 within the ITF promoter (74). Tumor hypoxia is a powerful and early signal for induction of the angiogenic switch $(9,10)$. Hypoxic regions of solid tumors trigger the induction of the heterotrimeric transcription factor hypoxia-inducible factor (HIF). The HIF-2 $\alpha$ subunit binds as a heterodimer with HIF-1 $\beta$ to the hypoxia response element of a wide variety of genes implicated in angiogenesis, cell proliferation, and survival including VEGF, Flt-1, endothelin-1, nitric oxide synthase 2, plasminogen inhibitor 1, and several elements of the IGF pathways (75). Activation of the $\alpha \beta$ HIF heterodimer is dependent on stabilization of an $\mathrm{O}_{2}$-dependent degradation domain of the $\alpha$ subunit by the ubiquitin-proteasome pathway (76). Thus, the constitutive overexpression of TFFs observed during the neoplastic progression in the digestive tract strongly suggests that they belong to the inflammation- and hypoxia-dependent proangiogenic factors released from tumor cells. Because TFFs are overexpressed in breast, prostate, and pancreatic tumors, our findings suggest a general role for TFFs in tumor angiogenesis and, possibly, in other physiopathological processes involving neovascularization.

\section{FJ}

Supported by INSERM, ARC (French Association for Cancer Research), research grants from Aventis-Pharma, AstraZeneca, the Funds voor Research in Oftalmologie (FRO), the FORTIS Verzekeringen, and the Fund for Scientific ResearchFlanders (FWO), Brussels, Belgium. S.R. is a Ph.D. student supported by the French Ministry of the Scientific Research; E.V.A. is a Research Assistant of the F.W.O. ZD1839 (Iressa), a trademark of the AstraZeneca group of companies, was kindly provided by AstraZeneca, Macclesfield, UK.

\section{REFERENCES}

1. André, T., Kotelevets, L., Vaillant, J. C., Coudray, A. M., Weber, L., Prevot, S., Parc, R., Gespach, C., Chastre, E. (2000) Vegf, Vegf-B, Vegf-C and their receptors KDR, FLT-1 and FLT-4 during the neoplastic progression of human colonic mucosa. Int. J. Cancer 86, 174-181

2. Podolsky, D. K. (1991) Inflammatory bowel disease (1). N. Engl. J. Med. 325, 928-937

3. Rudolph, U., Finegold, M. J., Rich, S. S., Harriman, G. R., Srinivasan, Y., Brabet, P., Boulay, G., Bradley, A., Birnbaumer, L. (1995) Ulcerative colitis and adenocarcinoma of the colon in G $\alpha_{\mathrm{i} 2}$-deficient mice. Nat. Genet. 10, 143-150

4. Okada, F., Kawaguchi, T., Habelhah, H., Kobayashi, T., Tazawa, H., Takeichi, N., Kitagawa, T., Hosokawa, M. (2000) Conversion of human colonic adenoma cells to adenocarcinoma cells through inflammation in nude mice. Lab. Invest. 80, 1617-1628

5. Folkman, J., Shing, Y. (1992) Angiogenesis. J. Biol. Chem. 267, 10931-10934

6. Carmeliet, P., Jain, R. K. (2000) Angiogenesis in cancer and other diseases. Nature (London) 407, 249-257

7. Lyden, D., Hattori, K., Dias, S., Costa, C., Blaikie, P., Butros, L., Chadburn, A., Heissig, B., Marks, W., Witte, L., et al. (2001) Impaired recruitment of bone-marrow-derived endothelial and hematopoietic precursor cells blocks tumor angiogenesis and growth. Nat. Med. 7, 1194-1201

8. Folkman, J. (1995) Angiogenesis in cancer, vascular, rheumatoid and other disease. Nat. Med. 1, 27-31

9. Hanahan, D., Folkman, J. (1996) Patterns and emerging mechanisms of the angiogenic switch during tumorigenesis. Cell 86, 353-364

10. Shweiki, D., Itin, A., Soffer, D., Keshet, E. (1992) Vascular endothelial growth factor induced by hypoxia may mediate hypoxia-initiated angiogenesis. Nature (London) 359, 843-845

11. Kung, A. L., Wang, S., Klco, J. M., Kaelin, W. G., Livingston, D. M. (2000) Suppression of tumor growth through disruption of hypoxia-inducible transcription. Nat. Med. 6, 1335-1340

12. Fidler, I. J., Ellis, L. M. (1994) The implications of angiogenesis for the biology and therapy of cancer metastasis. Cell 79, $185-188$

13. Ferrara, N., Alitalo, K. (1999) Clinical applications of angiogenic growth factors and their inhibitors. Nat. Med. 5, 13591364

14. Vinals, F., Pouyssegur, J. (2001) Transforming growth factor betal (TGF-beta1) promotes endothelial cell survival during in vitro angiogenesis via an autocrine mechanism implicating TGF-alpha signaling. Mol. Cell. Biol. 21, 7218-7230

15. Gupta, R. A., DuBois, R. N. (2001) Colorectal cancer prevention and treatment by inhibition of cyclooxygenase-2. Nat. Rev. Cancer 1, 11-21

16. Hoffmann, W., Jagla, W., Wiede, A. (2001) Molecular medicine of TFF-peptides: from gut to brain. Histol. Histopathol. 16, 319-334

17. Emami, S., Le Floch, N., Bruyneel, E., Thim, L., May, F., Westley, B., Rio, M. C., Mareel, M., Gespach, C. (2001) Induction of scattering and cellular invasion by trefoil peptides in src- and RhoA-transformed kidney and colonic epithelial cells. FASEB J. 15, 351-361

18. Tran, C. P., Cook, G. A., Yeomans, N. D., Thim, L., Giraud, A. S. (1999) Trefoil peptide TFF2 (spasmolytic polypeptide) potently accelerates healing and reduces inflammation in a rat model of colitis. Gut 44, 636-642

19. Rodrigues, S., Nguyen, Q. D., Faivre, S., Bruyneel, E., Thim, L., Westley, B., May, F., Flatau, G., Mareel, M., Gespach, C., et al. (2001) Activation of cellular invasion by trefoil peptides and src is mediated by cyclooxygenase- and thromboxane A2 receptordependent signaling pathways. FASEB J. 15, 1517-1528

20. Régnauld, K., Nguyen, Q. D., Vakaet, L., Bruyneel, E., Launay, J. M., Endo, T., Mareel, M., Gespach, C., Emami, S. (2002) G-protein $\alpha$ olf subunit promotes cellular invasion, survival, and neuroendocrine differentiation in digestive and urogenital epithelial cells. Oncogene 21, 4020-4031

21. Prest, S. J., May, F. E., Westley, B. R. (2002) The estrogenregulated protein, TFF1, stimulates migration of human breast cancer cells. FASEB J. 16, 592-594

22. Bossenmeyer-Pourie, C., Kannan, R., Ribieras, S., Wendling, C., Stoll, I., Thim, L., Tomasetto, C., Rio, M. C. (2002) The trefoil factor 1 participates in gastrointestinal cell differentiation by delaying G1-S phase transition and reducing apoptosis. J. Cell Biol. 157, 761-770

23. Liu, D., El-Hariry, I., Karayiannakis, A. J., Wilding, J., Chinery, R., Kmiot, W., McCrea, P. D., Gullick, W. J., Pignatelli, M. (1997) 
Phosphorylation of $\beta$-catenin and epidermal growth factor receptor by intestinal trefoil factor. Lab. Invest. 77, 557-563

24. Rio, M. C., Bellocq, J. P., Daniel, J. Y., Tomasetto, C., Lathe, R., Chenard, M. P., Batzenschlager, A., Chambon, P. (1988) Breast cancer-associated pS2 protein: Synthesis and secretion by normal stomach mucosa. Science 241, 705-708

25. Bonkhoff, H., Stein, U., Welter, C., Remberger, K. (1995) Differential expression of the pS2 protein in human prostate and prostate cancer: association with premalignant changes and neuroendocrine differentiation. Hum. Pathol. 26, 824-828

26. Machado, J. C., Nogueira, A. M., Carneiro, F., Reis, C. A., Sobrinho-Simoes, M. (2000) Gastric carcinoma exhibits distinct types of cell differentiation: an immunohistochemical study of trefoil peptides (TFF1 and TFF2) and mucins (MUC1, MUC2, MUC5AC, and MUC6). J. Pathol. 190, 437-443

27. Wang, D. G., Johnston, C. F., Liu, W. H., Sloan, J. M., Buchanan, K. D. (1997) Expression of a breast-cancer-associated protein (pS2) in human neuroendocrine tumours. Int. J. Cancer 74, 270-274

28. Colombel, M., Dante, R., Bouvier, R., Ribieras, S., Pangaud, C., Maréchal, J. M., Lasne, Y. (1999) Differential RNA expression of the pS2 gene in the human begnin and malignant prostatic tissue. J. Urol. 162, 927-930

29. Nunez, A. M., Berry, M., Imler, J. L., Chambon, P. (1989) The 5 'flanking region of the pS2 gene contains a complex enhancer region responsive to œestrogens, epidermal growth factor, a tumour promoter (TPA), the c-Ha-ras oncoprotein and the c-jun protein. $E M B O ~ J .8,823-829$

30. Taupin, D., Wu, D. C., Jeon, W. K., Devaney, K., Wang, T. C., Podolsky, D. K. (1999) The trefoil gene family are coordinately expressed immediate-early genes: EGF receptor- and MAP kinase-dependent interregulation. J. Clin. Invest. 103, R31-R38

31. Sierra-Honigmann, M. R., Nath, A. K., Murakami, C., GarciaCardena, G., Papapetropoulos, A., Sessa, W. C., Madge, L. A., Schechner, J. S., Schawbb, M. B., Polverini, P. J., et al. (1998) Biological action of leptin as an angiogenic factor. Science $\mathbf{2 8 1}$, $1683-1686$

32. Ciardiello, F., Caputo, R., Bianco, R., Damiano, V., Pomatico, G., De Placido, S., Bianco, A. R., Tortora, G. (2000) Antitumor effect and potentiation of cytotoxic drugs activity in human cancer cells by ZD-1839 (Iressa), an epidermal growth factor receptor-selective tyrosine kinase inhibitor. Clin. Cancer Res. 6 , 2053-2063

33. Rodrigues, S., Bruyneel, E., Nguyen, Q. D, Tournigand, C., Mareel, M., Emami, S., Gespach, C. (2001) Suppression of cellular invasion induced by the trefoil factor pS2, leptin, and the src oncogene by the epidermal growth factor receptor (EGF-R) tyrosine kinase inhibitor Iressa (ZD1839) and a dominant negative form of the EGF-R. Clin. Cancer Res. 7, Suppl. 3771 S (abstr. 584)

34. Passaniti, A., Taylor, R. M., Pili, R., Guo, Y., Long, P. V., Haney, J. A., Pauly, R. R., Grant, D. S., Martin, G. R. (1992) A simple, quantitative method for assessing angiogenesis and antiangiogenic agents using reconstituted basement membrane, heparin, and fibroblast growth factor. Lab. Invest. 67, 519-528

35. Maragoudakis, M. E., Panoutsacopoulou, M., Sarmonika, M. (1988) Rate of basement membrane biosynthesis as an index to angiogenesis. Tissue Cell 20, 531-539

36. Liekens, S., Neyts, J., De Clercq, E., Verbeken, E., Ribatti, D., Presta, M. (2001) Inhibition of fibroblast growth factor-2 induced vascular tumor formation by the acyclic nucleoside phosphonate cidofovir. Cancer Res. 61, 5057-5064

37. Harris-Hooker, S. A., Gajdusek, C. M., Wight, T. N., Schwartz, S. M. (1983) Neovascular responses induced by cultured aortic endothelial cells. J. Cell. Physiol. 114, 302-310

38. Mendenhall, W., Beaver, R. R. (1994) Introduction to Probability and Statistics, 9th Ed, 2.7. The box plot, pp. 91-95, Duxbury Press, Boston

39. Thim, L., Norris, K., Norris, F., Nielsen, P. F., Bjorn, S. E., Christensen, M., Petersen, J. (1993) Purification and characterization of the trefoil peptide human spasmolytic polypeptide (hSP) produced in yeast. FEBS Lett. 318, 345-352

40. Thim, L., Wöldike, H. F., Nielsen, P. F., Christensen, M., Lynch-Devaney, K., Podolsky, D. K. (1995) Characterization of human and rat intestinal trefoil factor produced in yeast. Biochemistry 34, 4757-4764
41. Chadwick, M. P., Westley, B. R., May, F. E. B. (1997) Homodimerization and hetero-oligomerization of the single-domain trefoil protein pNR-2/pS2 through cysteine 58. Biochem. J. 327, 117-123

42. Woodburn, J. R., Morris, C. Q., Kelly, H., Laight, A. (1998) EGF receptor tyrosine kinase inhibitors as anti-cancer agents-preclinical and early clinical profile of ZD1839. First International Conference on Inhibitors of Protein Kinases, Warsaw, September 1998. Cell. Mol. Biol. Lett. 3, 348-349

43. Binétruy-Tournaire, R., Demangel, C., Malavaud, B., Vassy, R., Rouyre, S., Kraemer, M., Plouët, J., Derbin, C., Perret, G., Mazié, J.-C. (2000) Identification of a peptide blocking vascular endothelial growth factor (VEGF)-mediated angiogenesis. EMBO J. 19, 1525-1533

44. Markowitz, S. D., Molkentin, K., Gerbic, C., Jackson, J., Stellato, T., Willson, J. K. V. (1990) Growth stimulation by coexpression of transforming growth factor- $\alpha$ and epidermal growth factorreceptor in normal and adenomatous human colon epithelium. J. Clin. Invest. 86, 356-362

45. Forgue-Lafitte, M. E., Laburthe, M., Chamblier, M. C., Moody, A. J., Rosselin, G. (1980) Demonstration of specific receptors for EGF-Urogastrone in isolated rat intestinal epithelial cells. FEBS Lett. 114, 243-246

46. Forgue-Lafitte, M. E., Kobari, L., Gespach, C., Chamblier, M. C., Rosselin, G. (1984) Characterization and repartition of epidermal growth factor-urogastrone receptors in gastric glands isolated from young and adult guinea pigs. Biochim. Biophys. Acta 798, 192-198

47. Ciardiello, F., Caputo, R., Bianco, R., Damiano, V., Fontanini, G., Cuccato, S., De Placido, S., Bianco, A. R., Tortora, G. (2001) Inhibition of growth factor production and angiogenesis in human cancer cells by ZD1839 (Iressa), a selective epiderma growth factor receptor tyrosine kinase inhibitor. Clin. Cancer Res. 7, 1459-1465

48. Banks, A. S., Davis, S. M., Bates, S. H., Myers, M. G. (2000) Activation of downstream signals by the long form of the leptin receptor. J. Biol. Chem. 275, 14563-14572

49. Williams, C. S., Luongo, C., Radhika, A., Zhang, T., Lamps, L. W., Nanney, L. B., Beauchamp, R. D., DuBois, R. N. (1996) Elevated cyclooxygenase-2 levels in Min mouse adenomas. Gastroenterology 111, 1134-1140

50. Eberhart, C. E., Coffey, R. J., Radhika, A., Giardiello, F. M., Ferrenbach, S., DuBois, R. N. (1994) Up-regulation of cyclooxygenase 2 gene expression in human colorectal adenomas and adenocarcinomas. Gastroenterology 107, 1183-1188

51. Kutchera, W., Jones, D. A., Matsunami, N., Groden, J., McIntyre, T. M., Zimmerman, G. A., White, R. L., Prescott, S. M. (1996) Prostaglandin $\mathrm{H}$ synthase 2 is expressed abnormally in human colon cancer: evidence for a transcriptional effect. Proc. Natl. Acad. Sci. USA 93, 4816-4820

52. DuBois, R. N., Tsujii, M., Bishop, P., Awad, J. A., Makita, K., Lanahan, A. (1994) Cloning and characterization of a growth factor-inducible cyclooxygenase gene from rat intestinal epithelial cells. Am. J. Physiol. 266, G822-G827

53. Masunaga, R., Kohno, H., Dhar, D. K., Ohno, S., Shibakita, M., Kinugasa, S., Yoshimura, H., Tachibana, M., Kubota, H., Nagasue, N. (2000) Cyclooxygenase-2 expression correlates with tumor neovascularization and prognosis in human colorectal carcinoma patients. Clin. Cancer Res. 6, 4064-4068

54. Williams, C. S., Tsujii, M., Reese, J., Dey, S. K., DuBois, R. N. (2000) Host cyclooxygenase-2 modulates carcinoma growth. J. Clin. Invest. 105, 1589-1594

55. Daniel, T. O., Liu, H., Morrow, J. D., Crews, B. C., Marnett, L. J. (1999) Thromboxane A2 is a mediator of cyclooxygenase-2 dependent endothelial migration and angiogenesis. Cancer Res. 59, $4574-4577$

56. Tsujii, M., DuBois, R. N. (1995) Alterations in cellular adhesion and apoptosis in epithelial cells overexpressing prostaglandin endoperoxide synthase 2. Cell 83, 493-501

57. Pai, R., Szabo, I. L., Soreghan, B. A., Atay, S., Kawanaka, H., Tarnawski, A. S. (2001) PGE(2) stimulates VEGF expression in endothelial cells via ERK2/JNK1 signaling pathways. Biochem. Biophys. Res. Commun. 286, 923-928

58. Pai, R., Soreghan, B., Szabo, I. L., Pavelka, M., Baatar, D., Tarnawski, A. S. (2002) Prostaglandin $E_{2}$ transactivates EGF 
receptor: A novel mechanism for promoting colon cancer growth and gastrointestinal hypertrophy. Nat. Med. 8, 289293

59. Labayle, D., Fischer, D., Vielh, P., Drouhin, F., Pariente, A., Bories, C., Duhamel, O., Trousset, M., Attali, P. (1991) Sulindac causes regression of rectal polyps in familial adenomatous polyposis. Gastroenterology 101, 635-639

60. Giardiello, F. M., Hamilton, S. R., Krush, A. J., Piantadosi, S., Hylind, L. M., Celano, P., Booker, S. V., Robinson, C. R., Offerhaus, G. J. A. (1993) Treatment of colonic and rectal adenomas with sulindac in familial adenomatous polyposis. N. Engl. J. Med. 328, 1313-1316

61. Jacoby, R. F., Marshall, D. J., Newton, M. A., Novakovic, K., Tutsch, K., Cole, C. E., Lubet, R. A., Kelloff, G. J., Verma, A.,Moser, A. R., et al. (1996) Chemoprevention of spontaneous intestinal adenomas in the $A p c^{\mathrm{Min}}$ mouse model by the nonsteroidal anti-inflammatory drug piroxicam. Cancer Res. 56, 710714

62. Jones, M. K., Wang, H., Peskar, B. M., Levin, E., Itani, R. M., Sarfeh, I. J., Tarnawski, A. S. (1999) Inhibition of angiogenesis by nonsteroidal anti-inflammatory drugs: Insight into mechanisms and implications for cancer growth and ulcer healing. Nat. Med. 5, 1418-1423

63. Liu, Y., Cox, S. R., Morita, T., Kourembanas, S. (1995) Hypoxia regulates vascular endothelial growth factor gene expression in endothelial cells. Identification of a $5^{\prime}$ enhancer. Circ. Res. 77, 638-643

64. Chua, C. C., Hamdy, R. C., Chua, B. H. (1998) Upregulation of vascular endothelial growth factor by angiotensin II in rat heart endothelial cells. Biochim. Biophys. Acta 1401, 187-194

65. Castilla, M. A., Alvarez Arroyo, M. V., Aceituno, E., Aragoncillo, P., Gonzalez-Pacheco, F. R., Texeiro, E., Bragado, R., Caramelo, C. (1999) Disruption of cadherin-related junctions triggers autocrine expression of vascular endothelial growth factor in bovine aortic endothelial cells. Circ. Res. 85, 1132-1138

66. Vega-Diaz, B., Herron, G. S., Michel, S. (2001) An autocrine loop mediates expression of vascular endothelial growth factor in human dermal microvascular endothelial cells. J. Invest. Dermatol. 116, 525-530
67. Cockerill, G. W., Meyer, G., Noack, L., Vadas, M. A., Gamble, J. R. (1994) Characterization of a spontaneously transformed human endothelial cell line. Lab. Invest. 71, 497-509

68. Gluzman-Poltorak, Z., Cohen, T., Herzog, Y., Neufeld, G. (2000) Neuropilin-2 and neuropilin-1 are receptors for the 165-amino acid form of vascular endothelial growth factor (VEGF) and of placenta growth factor-2, but only neuropilin-2 functions as a receptor for the 145-amino acid form of VEGF. J. Biol. Chem. 275, 18040-18045

69. He, Z., Tessier-Lavigne, M. (1997) Neuropilin is a receptor for the axonal chemorepellent Semaphorin III. Cell 90, 739-751

70. Kolodkin, A. L., Levengood, D. V., Rowe, E. G., Tai, Y. T., Giger, R. J., Ginty, D. D. (1997) Neuropilin is a semaphorin III receptor. Cell 90, 753-762

71. Soker, S., Takashima, S., Miao, H. Q., Neufeld, G., Klagsbrun, M. (1998) Neuropilin-1 is expressed by endothelial and tumor cells as an isoform-specific receptor for vascular endothelial growth factor. Cell 92, 735-745

72. Whitaker, G. B., Limberg, B. J., Rosenbaum, J. S. (2001) Vascular endothelial growth factor receptor-2 and neuropilin-1 form a receptor complex that is responsible for the differential signaling potency of VEGF(165) and VEGF(121). J. Biol. Chem. 276, 25520-25531

73. Attoub, S., Noë, V., Pirola, L., Bruyneel, E., Chastre, E., Mareel, M., Wymann, M. P., Gespach, C. (2000) Leptin promotes invasiveness of kidney and colonic epithelial cells via phosphoinositide 3-kinase-, Rho- and Rac-dependent signaling pathways. FASEB J. 14, 2329-2338

74. Furuta, G. T., Turner, J. R., Taylor, C. T., Hershberg, R. M., Comerford, K., Narravula, S., Podolsky, D. K., Colgan, S. P. (2001) Hypoxia-inducible factor 1-dependent induction of intestinal trefoil factor protects barrier function during hypoxia. $J$. Exp. Med. 193, 1027-1034

75. Gothié, E., Pouysségur, J. (2002) HIF-1: régulateur central de l'hypoxie. Méd./Sci. 18, 70-78

76. Huang, L. E., Gu, J., Schau, M., Bunn, H. F. (1998) Regulation of hypoxia-inducible factor 1 alpha is mediated by an $\mathrm{O}_{2}$ dependent degradation domain via the ubiquitin-proteasome pathway. Proc. Natl. Acad. Sci. USA 95, 7987-7992 